\title{
Nuclear Gamma Ray Resonance Observation of the Activation Process in Raney Iron and Urushibara Iron Catalysts
}

\author{
L. J. Swartzendruber \\ National Bureau of Standards, Gaithersburg, Maryland 20234 \\ AND \\ B. J. Evans \\ University of Michigan, Ann Arbor, Michigan 48104 \\ Received December 17, 1975
}

\begin{abstract}
The phases that form when Raney iron and Urushibara iron catalysts are activated have been studied utilizing ${ }^{57} \mathrm{Fe}$ nuclear gamma ray resonance. For Raney iron catalysts four phases are observed in the activated catalyst; residual aluminum-depleted Raney alloy, $\mathrm{Fe}(\mathrm{OH})_{2}$, $\alpha-\mathrm{Fe}$ and $\mathrm{Fe}_{3} \mathrm{O}_{4}$. The relative proportions of phases present is a sensitive function of leaching temperature and time. For Raney iron catalysts, and for Urushibara iron catalysts prepared using aluminum, no alloying of aluminum into the activated phases is observable. For Urushibara iron catalysts prepared using zinc, there is considerable alloying of iron and zinc. Evidence is presented to show that when the eatalyst is generated at low temperatures $\mathrm{Fe}(\mathrm{OH})_{2}$ is a precursor phase for metallic Fe in Raney Iron. A similar situation seems to exist for the Urushibara catalyst prepared using aluminum. The alloying behavior of the iron catalysts can be understood on the basis of the nature of the intermediate phase. The large amounts of $\mathrm{Fe}_{3} \mathrm{O}_{4}$ present in Raney iron prepared at elevated temperatures raises some questions concerning the catalytically active phases in such materials.
\end{abstract}

\section{INTRODUCTION}

The Raney-type metal catalysts consist primarily of very fine metal powders, which are unsupported and have been described as having a skeletal morphology (1). Even though Raney nickel is the most commonly used and versatile Raney catalyst and is employed in hydrogenation, dehalogenation and desulfuration reactions, Raney cobalt, Raney copper and Raney iron find selective applications in hydrogenation reactions. For example, Raney copper is used in the hydrogenation of aromatic nitro compounds to aromatic amines. Raney cobalt is employed in the ring hydrogenation of aromatic amines and Raney iron is highly selective in catalyzing the partial hydrogenation of alkynes to alkenes (2).

The Raney catalysts are typified not so much by a similarity in the structure, composition and morphology of the active phases as by (a) the technique used to generate the active phase and (b) the nature of the starting material. The starting material, as prepared commercially, is a metastable mixture of aluminum alloys of the appropriate transition metal. The overall composition of this mixture of alloys is 50 wt $\% \mathrm{Al}$ and $50 \mathrm{wt} \% \mathrm{Ni}$. This composition can vary by a few percent with respect to both components; and promoters are also added in some instances (3). This 
mixture of alloys in the form of a fine powder is treated with a $20 \% \mathrm{NaOH}$ solution at tempcratures between 50 to $110^{\circ} \mathrm{C}$ for several hours to gencrate the active catalyst. The treatment of the catalyst with the alkali solution has been referred to as a "leaching-out" of the aluminum, according to the equation

$2 \mathrm{H}_{2} \mathrm{O}+2 \mathrm{Al}+2 \mathrm{NaOH}$

$$
\rightarrow 2 \mathrm{NaAlO}_{2}+3 \mathrm{H}_{2} \text {. }
$$

While this is obviously an oversimplification of the process by which the active catalyst is generated, the designation of Raney catalysts as skeletal catalysts is based on the presumption that the aluminum is simply "leached-out" of the Ni-Al alloys, with the "skeleton" of metallic nickel that was passive during the leaching process remaining. As we shall see below, it is hardly likely that the generation of Raney iron can be usefully described as a leachingout of aluminum; our results are consistent with the production of intermediate nonmetallic phases, of substantial amounts of iron as atomic clusters or very fine cryptocrystalline particles which undergo further reactions and recrystallization to form the metallic particles in the catalyst. That the morphology of the resulting catalyst is reflective of differenecs in the morphology of particles of the starting multiphase alloy (3) is only incidental and is perhaps due to the short lifetime of the atomic clusters prior to recrystallization. There are no a priori reasons for believing that a similar situation would not apply to Raney nickel.

The preparation of the catalyst is effected with reasonable ease and reproducibility but wide variations in activities and selectivities can be obtained by variations in the preparation method, primarily in the time duration and temperature of the treatment with alkali. It has been shown (4-6) that high catalytic activity in Raney catalysts can be correlated with residual aluminum content. The residual aluminum, surface area, and catalytic activity have been observed to decrease with increasing leaching time and temperature $(3,7,8)$.

A number of very recent and systematic studies of Raney nickel alloys have been reported and much new information is available on the morphology and overall composition of Raney nickel catalysts $(3, \gamma-9)$. There is little hope of understanding further the character of the Raney-type catalysts unless various stages in the preparation of the catalyst can be followed at the atomic level. However, rather than restrict our studies to Raney catalysts, we have chosen to carry out a comparative study on the Raney and Urushibara catalysts (10). The Urushibara catalysts are very similar to the Raney catalysts in their activities and selectivities, and there are Urushibara analogues for each of the Raney catalysts. The method of preparation of the Urushibara catalysts is on cursory inspection, however, quite different from that of the Raney catalysts, involving the solution reduction of the appropriate transition metal salt, i.e., $\mathrm{FeCl}_{2}, \mathrm{FeCl}_{3}, \mathrm{NiCl}_{2}$, etc., with $\mathrm{Al}$ or $\mathrm{Zn}$ metal powders. The amount of $\mathrm{Al}$ or $\mathrm{Zn}$ powder is considerably in excess of the $50 \mathrm{wt} \%$ used in the preparation of Raney catalysts. This mixture of reduced transition metal and excess reducing agent is treatcd ("lcached") with acetic acid or base and the active catalyst results. It is quite likely that prior to the treatment with acetic acid or base, the precursor materials for the Urushibara catalysts are very similar to the Raney alloys. That is to say, the transition metal is extensively alloyed with aluminum or zinc. It appears that the treatment of the Urushibara precursor material with acetic acid or base results in the removal of excess reducing agent as well as the removal of alloyed reducing agent. In fact, as we shall see below, when $Z_{n}$ is used as the reducing agent for iron salts, the treatment with acetic acid or base does not result in the complete removal of alloyed $\mathrm{Zn}$ and a $\mathrm{Fe}-\mathrm{Zn}$ alloy is readily detected in the Urushibara catalyst. 
It is possible to gain some further insights at the atomic level into the effect of the method of $\mathrm{Al}$ removal process on the chemistry and metallurgy of Raney and Urushibara catalysts by means of nuclear gamma ray resonance (NGR) spectroseopy (Mössbauer effect). ${ }^{57} \mathrm{Fe}$ NGR was chosen to study these catalysts because the ${ }^{57} \mathrm{Fe}$ NGR spectrum is sensitive to both structure and composition in the $\mathrm{Fe}-\mathrm{Al}$ system $(11-15)$ and in the $\mathrm{Fe}-\mathrm{Al}-\mathrm{O}$ system $(16-18)$. Furthermore, using ${ }^{57} \mathrm{Fe}$ NGR spectroscopy the effects of various heat treatments on the structure and chemistry of these phases can be followed even for poorly crystalline and multiphase materials. Even though Raney iron is of less technical importance than Raney nickel, Raney iron and Urushibara iron have been chosen in this first attempt at a systematic study because of the case of performing ${ }^{57} \mathrm{Fe}$ NGR measurements. ${ }^{11} \mathrm{Ni}$ NGR studies of Rancy nickel are in the planning stage.

There have recently been several NGR studies on supported iron-containing catalysts (19-21). Unsupported Raney and Urushibara iron catalysts have not been as extensively investigated using NGR. Prior to the present program of investigation, only one study on Rancy iron had been reported (22). Nonetheless, recent work (22, 23) has shown that this method yields considerable information concerning the chemical and metallurgical state of the iron catalysts as well as the dynamics of the aluminum removal process. In this paper we compare results obtained on various Raney iron and Urushibara iron catalysts. Most significant among our findings are: (a) the absence of aluminum alloying in activated Raney iron catalysts and in Urushibara iron catalysts prepared using aluminum, (b) the extensive alloying of $\mathrm{Fe}$ and $\mathrm{Zn}$ in Urushibara iron catalysts prepared using zinc, and (c) the absence of oxide phases of $\mathrm{Fe}$ in the activated cataIysts when leached at or below about $70^{\circ} \mathrm{C}$. Alloys of $\mathrm{FeAl}, \mathrm{FeAl}_{2}$ and $\mathrm{Fe}_{2} \mathrm{Al}_{5}$ were also synthesized and detailed comparison of their NGR spectra is made with the spectrum obtained from the parent $\mathrm{Fe}-\mathrm{Al}$ Raney alloy.

\section{EXPERIMENTAL METHODS}

\section{Sample Preparation}

For the Raney iron catalysts, an $\mathrm{Fe}-\mathrm{Al}$ Raney iron alloy with 50 wt\% $\mathrm{Fe}$ and $50 \mathrm{wt} \%$ Al was obtained from a commercial source. The alloy was treated with $\mathrm{NaOH}$ in several different ways as indicated below :

Sample $R-F e-A$. This sample of Raney iron catalyst was prepared by slowly adding $50 \mathrm{~g}$ of the alloy to a $25 \% \mathrm{NaOH}$ solution prepared using $50 \mathrm{~g}$ of $\mathrm{NaOH}$. The temperature of the solution was maintained between 45 and $55^{\circ} \mathrm{C}$ during the addition of the alloy. The temperature was then raised to $90^{\circ} \mathrm{C}$ and held constant for 90 min. After decanting the supernatant liquid, the solid resulting from the above treatment was washed with distilled water several times with the liquid being decanted after each washing. The solid was then treated with fresh $25 \% \mathrm{NaOH}$ solution at a temperature of $95^{\circ} \mathrm{C}$ for $60 \mathrm{~min}$. Hydrogen was still being evolved at the end of this period. The solid was then washed with distilled water until the supernatant liquid had a $\mathrm{pH} \sim 7$. The sample was then stored under absolute ethanol.

Sample $R-F e-B$. This sample was treated in a manner identical to that of $\mathrm{R}-\mathrm{Fe}-\mathrm{A}$ except that the second treatment with the $25 \% \mathrm{NaOH}$ solution was for a period of $12 \mathrm{hr}$, at the end of which time the evolution of hydrogen had ceased. After washing with distilled water the resulting solid was stored under absolute ethanol.

Sample $R-F e-C$. This sample was prepared by slowly adding the $\mathrm{Fe}-\mathrm{Al}$ Raney alloy to a $25 \% \mathrm{NaOH}$ solution at $25^{\circ} \mathrm{C}$, and maintaining this temperature for $90 \mathrm{~min}$. (Hydrogen evolution had not ceased at the end of this time period.) The resulting solid was washed until the supernatant liquid had a $\mathrm{pH} \sim 7$ and then stored under absolute ethanol. 
TABLE 1

Summary of Preparation Procedures ${ }^{a}$

\begin{tabular}{|c|c|c|c|}
\hline \multirow[t]{2}{*}{ Sample } & \multirow[t]{2}{*}{ Starting material } & \multicolumn{2}{|c|}{ Leaching } \\
\hline & & First & Second \\
\hline R-Fe-A & Raney alloy & $25 \% \mathrm{NaOH}, 90^{\circ} \mathrm{C}, 90 \mathrm{~min}$ & $25 \% \mathrm{NaOH}, 95^{\circ} \mathrm{C}, 60 \mathrm{~min}$ \\
\hline $\mathrm{R}-\mathrm{Fe}-\mathrm{B}$ & Raney alloy & $25 \% \mathrm{NaOH}, 90^{\circ} \mathrm{C}, 90 \mathrm{~min}$ & $25 \% \mathrm{NaOH}, 95^{\circ} \mathrm{C}, 12 \mathrm{hr}$ \\
\hline $\mathrm{R}-\mathrm{Fe}-\mathrm{C}$ & Raney alloy & $25 \% \mathrm{NaOH}, 25^{\circ} \mathrm{C}, 90 \mathrm{~min}$ & None \\
\hline R-Fe-D & Raney alloy & $25 \% \mathrm{NaOH}, 25^{\circ} \mathrm{C}, 90 \mathrm{~min}$ & $25 \% \mathrm{NaOH}, 80^{\circ} \mathrm{C}, 45 \mathrm{~min}$ \\
\hline R-Fe-E & Raney alloy & $25 \% \mathrm{NaOH}, 0^{\circ} \mathrm{C}, 90 \mathrm{~min}$ & None \\
\hline R-Fe-F & Raney alloy & $25 \% \mathrm{NaOH}, 0^{\circ} \mathrm{C}, 90 \mathrm{~min}$ & $10 \% \mathrm{NaOH}, 0^{\circ} \mathrm{C}, 12 \mathrm{hr}$ \\
\hline $\mathrm{R}-\mathrm{Fe}-\mathrm{G}$ & Raney alloy & $25 \% \mathrm{NaOH}, 0^{\circ} \mathrm{C}, 90 \mathrm{~min}$ & $25 \% \mathrm{NaOH}, 70^{\circ} \mathrm{C}, 10 \mathrm{~min}$ \\
\hline $\mathrm{U}-\mathrm{Fe}(\mathrm{III})-\mathrm{BA}$ & $\mathrm{FeCl}_{3}+\mathrm{Al}$ & $20 \% \mathrm{NaOH}, 50^{\circ} \mathrm{C}, 60 \mathrm{~min}$ & None \\
\hline U-Fe(II) & $\mathrm{FeCl}_{2}+\mathrm{Zn}$ & $15 \%$ Acetic, $65^{\circ} \mathrm{C}, 20 \mathrm{~min}$ & None \\
\hline $\mathrm{U}-\mathrm{Fe}$ (III) & $\mathrm{FeCl}_{3}+\mathrm{Zn}$ & $15 \%$ Acetic, $65^{\circ} \mathrm{C}, 20 \mathrm{~min}$ & None \\
\hline
\end{tabular}

a For a full description of sample treatment, see text.

Sample $R-F e-D$. This sample was prepared by treating R-Fe-C at $80^{\circ} \mathrm{C}$ for 45 min with a $25 \% \mathrm{NaOH}$ solution. Hydrogen evolution was still evident at the end of this period. The resulting solid was washed as described previously and stored under absolute ethanol.

Sample $R-F e-E$. This sample was prepared in a manner similar to that used for $\mathrm{R}-\mathrm{Fe}-\mathrm{D}$, except that the temperature was maintained at $0^{\circ} \mathrm{C}$ during the treatment with $\mathrm{NaOH}$. After washing, the resulting solid was stored under absolute ethanol.

Sample $R-F e-F$. 'This sample resulted from the treatment of $\mathrm{R}-\mathrm{Fe}-\mathrm{E}$ in a $10 \%$ $\mathrm{NaOH}$ solution for an additional $12 \mathrm{hr}$ at $\sim 0^{\circ} \mathrm{C}$. The resulting material was washed and stored under absolute ethanol.

Sample $R-F e-G$. This sample resulted from the treatment of $\mathrm{R}-\mathrm{Fe}-\mathrm{E}$ in a $25 \%$ $\mathrm{NaOH}$ solution for $10 \mathrm{~min}$ at $70^{\circ} \mathrm{C}$. Hydrogen evolution was still evident at the end of this treatment.

The Urushibara catalysts were prepared precisely according to the methods given by Hata (10) and we use his notations to denote the resulting catalysts. The U$\mathrm{Fe}(\mathrm{III})$ and $\mathrm{U}-\mathrm{Fe}(\mathrm{II})$ catalysts were prepared by adding $\mathrm{FeCl}_{3} \cdot \mathrm{H}_{2} \mathrm{O}$ and $\mathrm{FeCl}_{2} \cdot \mathrm{H}_{2} \mathrm{O}$ powders, respectively, to a slurry of zinc dust and distilled $\mathrm{H}_{2} \mathrm{O}$. The U-Fe(III)-BA catalyst was prepared by adding $\mathrm{FeCl}_{3} \cdot \mathrm{H}_{2} \mathrm{O}$ to a slurry of aluminum powder (100 mesh) in distilled $\mathrm{H}_{2} \mathrm{O}$. The resulting solids were leached with acetic acid or $\mathrm{NaOH}$ and washed with ethanol. The catalyst sample preparation procedures are summarized in Table 1.

The Urushibara catalysts were not exposed to air as dry powders, except for one sample of U-Fe(III) that was exposed as a dry powder to air for $72 \mathrm{hr}$ to determine its sensitivity to air oxidation. The solutions were not deaerated during preparation.

\section{Nuclear Gamma Ray Resonance Technique}

The NGR absorbers were prepared by making $25 \mathrm{~mm}$ diameter dises on $0.025 \mathrm{~mm}$ thick Mylar film using ethanol slurries of the samples described above. To prevent exposure of the catalyst particles to air, a mixture of Duco cement and acetone was added to the slurry and this mixture was permitted to dry in air.

The NGR spectra were obtained in transmission mode utilizing a $5 \mathrm{mCi}{ }^{57} \mathrm{Co} / \mathrm{Pd}$ source. The spectrometer was periodically calibrated using a pure iron foil as a reference. Alloys of $\mathrm{FeAl}, \mathrm{FeAl}_{2}, \mathrm{Fe}_{2} \mathrm{Al}_{5}$, and $\mathrm{FeAl}_{3}$ were prepared by casting followed by a homogenization heat treatment. 
These alloys were examined metallographically and found to be single phase. They were ground to a 200 mesh powder and mounted in a thermosetting plastic for observation by transmission NGR. The samples were such that spectral area ratios are approximately equal to the proportion of phases present.

\section{RESULTS}

\section{Raney Iron Alloys and Catalysts}

The NGR spectrum for the untreated, parent $\mathrm{Fe}-\mathrm{Al}$ Raney alloy is shown in Fig. 1a. The points represent experimental data and the solid line is a least-meansquares fit to a theoretical spectrum. The least-mean-squares fitting technique is an iterative procedure and has been previously described (24). For Fig. 1a the theoretical spectrum consisted of two Lorentzian shaped lines, each line being represented by the equation

$$
f(v)=\frac{I}{(2 / \Gamma)^{2}\left(v-v_{0}\right)^{2}+1},
$$

where $f(v)$ is the resonance absorption for a relative velocity $v$ between source and absorber (for source and absorber approaching the sign of the velocity is considered positive), $\Gamma$ is the full width at half maximum, $v_{0}$ is the center of the line (with respect to the center of gravity of the spectrum of pure iron for all spectra presented here), and $I$ represents the relative height of the absorption peak. The very slight deviation from the theoretical curve apparent in Fig. 1a is due in part to the fact that the lines are not exactly Lorentzian in shape and partly to the fact that more than one $\mathrm{Fe}-\mathrm{Al}$ intermetallic phase is present. Figure $1 \mathrm{~b}, \mathrm{c}$, and $\mathrm{d}$ show spectra of $\mathrm{FeAl}_{3}, \mathrm{Fe}_{2} \mathrm{Al}_{5}$, and $\mathrm{FeAl}_{2}$, respectively, fitted in the same manner as Fig. 1a. Figure 1e shows the spectrum of FeAl fitted to a single Torentzian line. Figure if shows the spectrum obtained from sample R-Fe-E. The parameters obtained by least-squares

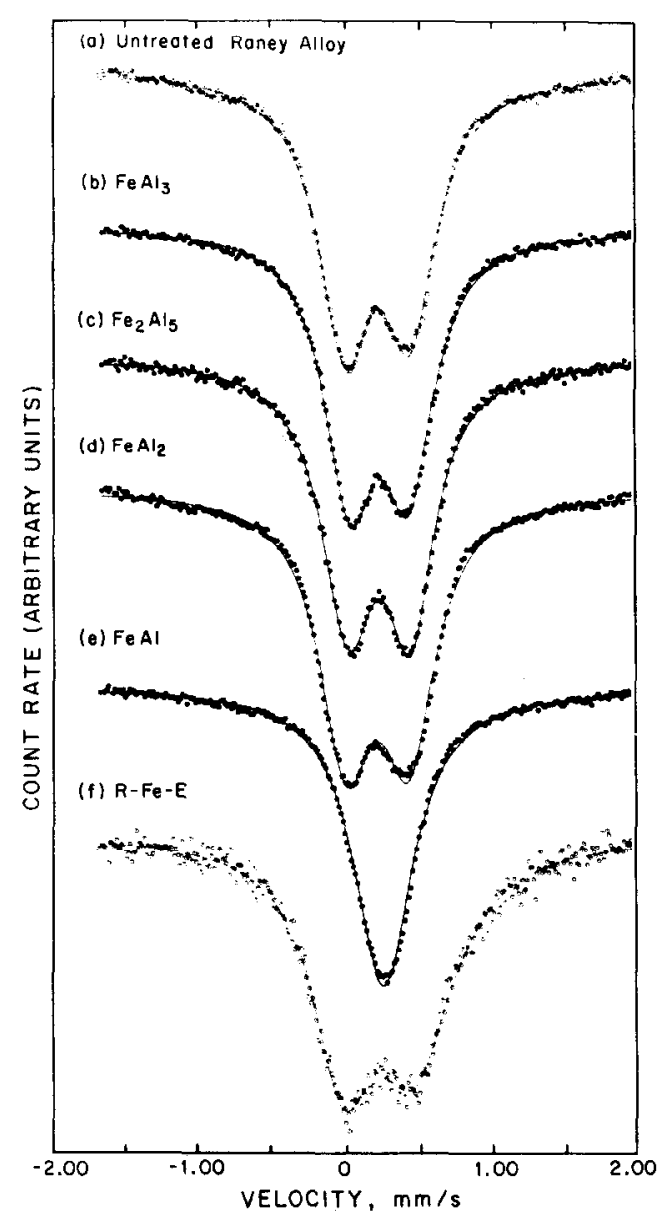

FIG. 1. NGR spectra ubluined at $23^{\circ} \mathrm{C}$ for $\mathrm{Fe}-\mathrm{Al}$ alloys and for Raney iron alloy leached at $0^{\circ} \mathrm{C}$ for $90 \mathrm{~min}$. $(\mathrm{O},-)$ Experimental data $(-)$ a leastmean-squares fit obtained as described in the text. The zero of velocity represents the center of a spectrum of pure iron at $23^{\circ} \mathrm{C}$. (a) Untreated parent Fe-Al Raney Alloy; (b) $\mathrm{FeAl}_{3}$; (c) $\mathrm{Fe}_{2} \mathrm{Al}_{5}$, (d) $\mathrm{FeAl}_{2}$, (e) $\mathrm{FeAl}$, and (f) Re-Fe-E (parent Raney alloy leached in sodium hydroxide for $90 \mathrm{~min}$ at $0^{\circ} \mathrm{C}$ ).

fitting the spectra of Fig. 1 are given in Table 2. All the spectra, except that for $\mathrm{FeAl}$, are quadrupole doublets due to an electric field gradient at the iron nucleus. For $\mathrm{FeAl}$, which has the $\mathrm{CsCl}$ ordered structure, the Fe atoms are in sites of cubic symmetry; no electric field gradient is present and only a single line spectrum is obtained.

The spectrum and fit obtained for sample $\mathrm{R}-\mathrm{Fe}-\mathrm{A}$ are shown in Fig. 2a. This spectrum 
TABLE 2

Parameters Obtained by Least Squares Fitting the Fe-Al Alloy Spectra of

Fig. 1 Using the Method Described in the Text ${ }^{a}$

\begin{tabular}{lcccccc}
\hline Sample & $\begin{array}{c}\text { Line } \\
\text { No. }\end{array}$ & $\begin{array}{c}\text { Linewidth } \\
\Gamma(\mathrm{mm} \mathrm{s} \\
\pm 0.01)\end{array}$ & $\begin{array}{c}\text { Position } \\
V_{0}\left(\mathrm{~mm} \mathrm{~s}^{-1}\right. \\
\pm 0.01)\end{array}$ & $\begin{array}{c}\text { Relative } \\
\text { absorption } \\
\text { area } \\
\pm 0.02\end{array}$ & $\begin{array}{c}\text { Quadrupole } \\
\text { splitting } \\
\left(\mathrm{mm} \mathrm{s}^{-1}\right. \\
\pm 0.01)\end{array}$ & $\begin{array}{c}\text { Isomer } \\
\text { shift } \\
\left(\mathrm{mm} \mathrm{s}^{-1}\right. \\
\pm 0.01)\end{array}$ \\
\hline $\begin{array}{l}\text { Parent Raney } \\
\text { iron alloy }\end{array}$ & 1 & 0.44 & 0.01 & 0.53 & 0.44 & 0.22 \\
$\mathrm{FeAl}_{3}$ & 2 & 0.42 & 0.45 & 0.47 & & \\
& 1 & 0.42 & 0.03 & 0.52 & 0.40 & 0.23 \\
$\mathrm{Fe}_{2} \mathrm{Al}_{5}$ & 2 & 0.41 & 0.43 & 0.48 & & \\
$\mathrm{FeAl}_{2}$ & 1 & 0.44 & 0.01 & 0.53 & 0.43 & 0.23 \\
& 2 & 0.45 & 0.44 & 0.47 & & \\
$\mathrm{FeAl}$ & 1 & 0.44 & 0.00 & 0.50 & 0.43 & 0.21 \\
$\mathrm{R}-\mathrm{Fe}-\mathrm{E}$ & 2 & 0.45 & 0.43 & 0.50 & & 0.26 \\
& 1 & 0.49 & 0.26 & 1.0 & - & 0.21 \\
\hline
\end{tabular}

${ }^{a}$ Isomer shifts and line positions are with respect to pure iron at $23^{\circ} \mathrm{C}$. Errors listed are two standard deviations.

was least-squares fitted to three magnetic hyperfine field patterns. Such patterns are characteristic of the NGR spectra for iron

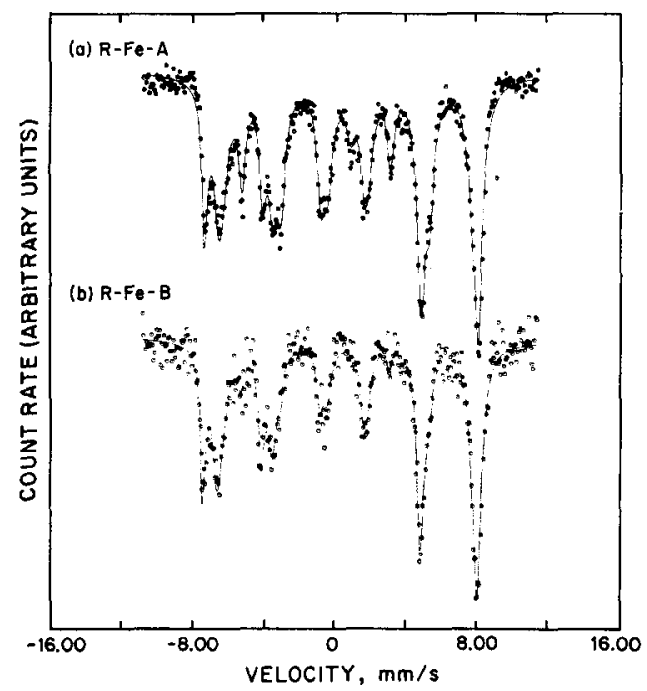

FIG. 2. NGR spectra obtained at $23^{\circ} \mathrm{C}$ for the two activatcd Raney iron catalysts $\mathrm{R}-\mathrm{Fe}-\mathrm{A}$ and $\mathrm{R}-\mathrm{Fe}-\mathrm{B}$. (O) Experimental data; (-) a least-mean-squares fit obtained as described in the text. The zero of velocity represents the center of a spectrum of pure iron at $23^{\circ} \mathrm{C}$. (a) Sample R-Re-A, Raney iron leached at $90^{\circ} \mathrm{C}$ for $90 \mathrm{~min}$ and at $95^{\circ} \mathrm{C}$ for $60 \mathrm{~min}$; (b) sample R-Fe-B, Raney iron leached at $90^{\circ} \mathrm{C}$ for $90 \mathrm{~min}$ and at $95^{\circ} \mathrm{C}$ for $12 \mathrm{hr}$. in a magnetically ordered material and consist of six lines of Lorentzian shape with relative positions and intensities determined by nuclear characteristics (25). For cach pattern, lines 1 and 6 , lines 2 and 5 , and lines 3 and 4 , respectively, were constrained to have the same intensity and width. The intensities and widths of each pair of lines were independent of those of any other pair of lines. All other parameters were allowed to vary independently. The two six-line patterns with the larger hyperfine fields arise from a magnetite-like phase and the one with the lowest field arises from a metallic iron phase. The spectrum and fit for R-Fe-B are shown in Fig. $2 b$. Again two phases are evident, a magnetitelike phase and a metallic-iron phase. The parameters obtained by the least-squares fitting are given in Table 3 . From the spectra of Fig. 2 it can be seen that the longer leaching period of R-Fe-B has increased the proportion of the oxide phase.

The NGR spectrum of sample $\mathrm{R}-\mathrm{Fe}-\mathrm{C}$, which was not heated during the leaching process, is shown in Fig. 3a. This spectrum was least-squares fitted to one magnetic hyperfine field (with the same constraints 
TABLE 3

Parameters Obtained by Least-Squares Fitting the Activated Raney Iron Spectra of Fig. 2 Using the Method Described in the Text ${ }^{u}$

\begin{tabular}{|c|c|c|c|c|c|}
\hline Sample & Phase & $\begin{array}{l}\text { Hyperfine } \\
\text { field } \\
(\mathrm{kG} \pm 6)\end{array}$ & $\begin{array}{l}\text { Linewidth } \Gamma \\
\left(\mathrm{mm} \mathrm{s} \mathrm{s}^{-1}\right. \\
\pm 0.08)\end{array}$ & $\begin{array}{l}\text { Isomer shift } \\
\qquad\left(\mathrm{mm} \mathrm{s}^{-1}\right. \\
\pm 0.0 \overline{5})\end{array}$ & $\begin{array}{c}\text { Relative } \\
\text { area } \\
\pm 0.05\end{array}$ \\
\hline \multirow{3}{*}{$\mathrm{R}-\mathrm{Fe}-\mathrm{A}$} & Magnetite & 479 & 0.38 & 0.34 & 0.22 \\
\hline & & 445 & 0.90 & 0.66 & 0.57 \\
\hline & Iron metal & 328 & 0.45 & 0.00 & 0.21 \\
\hline \multirow{3}{*}{ R-Fe-B } & Magnetite & 481 & 0.35 & 0.35 & 0.30 \\
\hline & & 449 & 0.81 & 0.67 & 0.64 \\
\hline & Iron metal & 328 & 0.47 & -0.01 & 0.06 \\
\hline
\end{tabular}

${ }^{a}$ Isomer shifts are with respect to pure iron at $23^{\circ} \mathrm{C}$. Errors are estimated at the two-sigma level. The linewidths given are those obtained for the outer two lines of each six-line magnetic hyperfine field pattern.

used for fitting the magnetic hyperfine spectra of samples R-Fe-A and B) and two single Lorentzian peaks. The large central peak near the center of the spectrum is the envelope of one of the lines from the quadrupole doublet due to $\mathrm{Fe}(\mathrm{OH})_{2}$, and of the spectrum from residual Raney iron alloy. The line at $\sim 2.5 \mathrm{~mm} \mathrm{~s}^{-1}$ is the other peak of the $\mathrm{Fc}(\mathrm{OH})_{2}$ symmetric doublet (26). The NGR spectrum of R-Fe-D, which was prepared from R-Fe-C with an additional leaching at $80^{\circ} \mathrm{C}$ for $45 \mathrm{~min}$, is shown in Fig. 3b. The parameters obtained in the least-squares fit to the data of Fig. 3a and $\mathrm{b}$ are given in Table 4 . It is worthy of note that the effect of digesting $\mathrm{R}-\mathrm{Fe}-\mathrm{C}$ at a higher temperature is to reduce the amounts of both $\mathrm{Fe}(\mathrm{OH})_{2}$ and $\mathrm{Fe}-$ metal and to increase the amount of $\mathrm{Fe}_{3} \mathrm{O}_{4}$ which was completely absent in R-Fe-C. This result is in agreement with the known decomposition of $\mathrm{Fe}(\mathrm{OH})_{2}$ at elevated temperatures according to the reaction $(2 \gamma)$ :

$$
3 \mathrm{Fe}(\mathrm{OH})_{2} \rightarrow \mathrm{F}_{\mathrm{C}_{3} \mathrm{O}_{4}}+\mathrm{H}_{2}+2 \mathrm{H}_{2} \mathrm{O} \text {. }
$$

This reaction is also known to be catalyzed by the fine particles of certain metals (28).

The NGR spectra for samples R-Fe-E, $F$ and $G$ are shown in Fig. 4. All these samples were given an initial treatment with alkali at $0^{\circ} \mathrm{C}$ for $90 \mathrm{~min}$. Samples $\mathrm{F}$ and $\mathrm{G}$ were given subsequent treatments at $0^{\circ} \mathrm{C}$ for $12 \mathrm{hr}$ and at $70^{\circ} \mathrm{C}$ for $10 \mathrm{~min}$, respectively. The parameters obtained by least-squares fitting the spectra of Fig. 4 are listed in Table 5. The spectrum for R-Fe-E was fitted to two Lorentzian peaks. As can be scen from the spectra and Table 5 , no metallic iron or iron oxides were de-

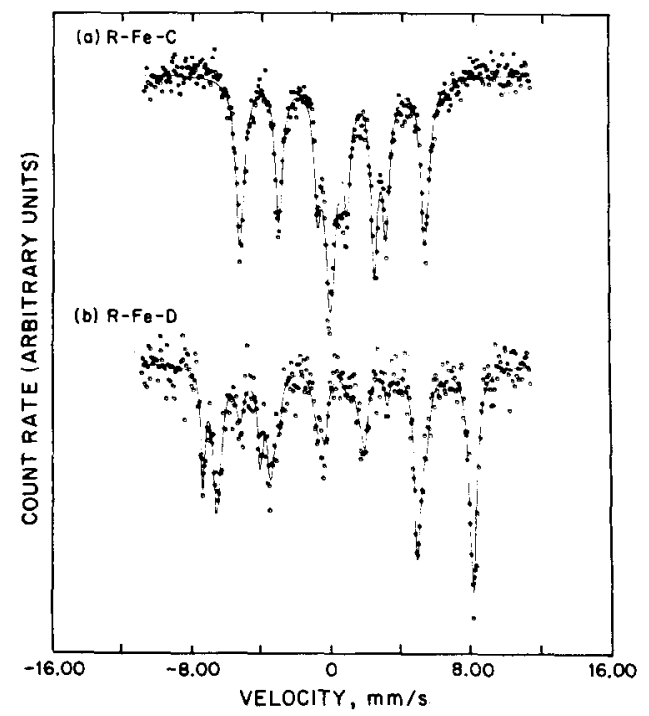

Fig. 3. NGR spectra obtained at $23^{\circ} \mathrm{C}$ for the two activated Raney iron catalysts R-Fe-C and R-Fe-D. (O) Experimental data; $(\longrightarrow)$ a least-mean-squares fit obtained as described in the text. The zero of velocity represents the center of a spectrum from pure iron at $23^{\circ} \mathrm{C}$. (a) Sample R-Fe-C leached at $25^{\circ} \mathrm{C}$ for $90 \mathrm{~min}$; (b) sample $\mathrm{R}-\mathrm{Fe}-\mathrm{D}$ ) which was prepared from $1 \mathrm{R}-\mathrm{Fe}-\mathrm{C}$ by an additional leach at $80^{\circ} \mathrm{C}$ for $45 \mathrm{~min}$. 
TABLE 4

Parameters Obtained by Least-Squares Fitting Activated Raney Iron Spectra of Fig. 3 Using the Method Described in the Text ${ }^{a}$

\begin{tabular}{clccccc}
\hline Sample & \multicolumn{1}{c}{ Phase } & $\begin{array}{c}\text { Quadrupole } \\
\text { splitting } \\
\left(\mathrm{mm} \mathrm{s}^{-1}\right. \\
\pm 0.05)\end{array}$ & $\begin{array}{c}\text { Hyperfine } \\
\text { field } \\
(\mathrm{kG} \pm 6)\end{array}$ & $\begin{array}{c}\text { Linewidth } \\
\left(\mathrm{mm} \mathrm{s}^{-1}\right. \\
\pm 0.08)\end{array}$ & $\begin{array}{c}\text { Isomer shift } \\
\left(\mathrm{mm} \mathrm{s}^{-1}\right. \\
\pm 0.05)\end{array}$ & $\begin{array}{c}\text { Relative } \\
\text { area } \\
\pm 0.05\end{array}$ \\
\hline R-Fe-C & $\begin{array}{l}\text { Iron metal } \\
\text { Peak 1 } \\
{\left[\mathrm{Fe}(\mathrm{OH})_{2}+\mathrm{Fe}-\mathrm{Al}\right]}\end{array}$ & - & - & 0.77 & -0.05 & 0.25 \\
& $\begin{array}{l}\text { Peak 2 } \\
{\left[\mathrm{Fe}(\mathrm{OH})_{2}\right]}\end{array}$ & - & - & 0.46 & 2.42 & 0.12 \\
& & & & & & \\
& & 0.00 & 483 & 0.30 & 0.36 & 0.29 \\
$\mathrm{R}-\mathrm{Fe}-\mathrm{D})$ & Magnetite & 0.00 & 453 & 0.59 & 0.68 & 0.55 \\
& Iron metal & 0.00 & 330 & 0.57 & 0.02 & 0.16 \\
\hline
\end{tabular}

${ }^{a}$ Isomer shifts are with respect to pure iron at $23^{\circ} \mathrm{C}$. Errors are estimated at the two-sigma level. For the magnetic hyperfine field spectra, the linewidths given are for the outer two lines of the six-line spectrum.

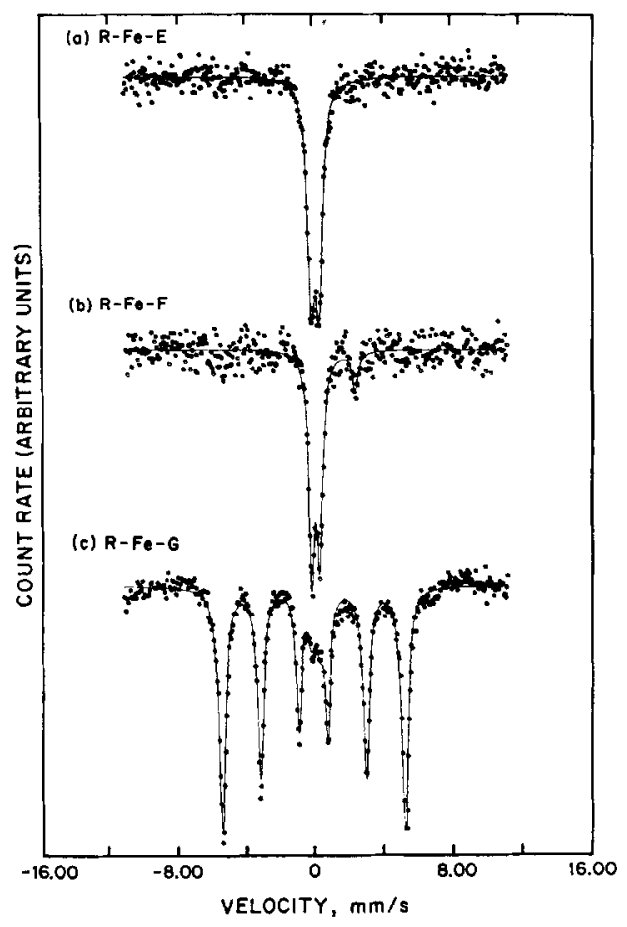

FIG. 4. NGR spectra obtained at $23^{\circ} \mathrm{C}$ for activated Raney iron catalysts R-Fe-E, R-Fe-F and R-Fe-G. (O) Experimental data; ( $\longrightarrow$ ) a leastmean-squares fit obtained as described in the text. The zero of velocity represents the center of a spectrum from pure iron at $23^{\circ} \mathrm{C}$. (a) Sample R-Fe-E leached at $0^{\circ} \mathrm{C}$ for $90 \mathrm{~min}$; (b) sample R-Fe-F leached at $0^{\circ} \mathrm{C}$ for a total of $13.5 \mathrm{hr}$; (c) sample $\mathrm{R}-\mathrm{Fe}-\mathrm{G}$, same as R-Fe-E but given an additional leach at $70^{\circ} \mathrm{C}$ for $10 \mathrm{~min}$. tected for leaching at $0^{\circ} \mathrm{C}$, even though considerable hydrogen is evolved. The parameters obtained for R-Fe-E are, within experimental error, identical to those obtained for the initial Raney iron alloy, except that the peak at lower velocity is slightly enhanced, possibly due to the presence of a small amount of $\mathrm{Fe}(\mathrm{OH})_{2}$. The spectrum of R-Fe-F was fitted to three Lorentzian peaks. The peak at lower velocity is a superposition of one peak from the Raney iron alloy doublet and one peak from the $\mathrm{Fe}(\mathrm{OH})_{2}$ doublet. In fitting the $\mathrm{R}-\mathrm{Fe}-\mathrm{G}$ spectrum, peak positions and linewidths corresponding to those found for the parent Raney iron alloy were assumed and held constant during the least-squares fitting; and the amplitudes were varied independently.

\section{Urushibara Iron Catalysts}

The spcetra and least-squares fits obtained from samples U-Fe(III)-BA, U$\mathrm{Fe}$ (II), and U-Fe(III) are shown in Fig. 5. The spectrum from U-Fe(III)-BA, Fig. 5a was fitted to a single six-line hyperfine field pattcrn. The spectral parameters are given in Table 6 and are, within experimental error, indistinguishable from those obtained for pure $\alpha-\mathrm{Fe}$. The spectra from 
TABLE 5

Parameters Obtained by Least-Squares Fitting the Spectra of Fig. 4 Using the Method Described in the Text ${ }^{a}$

\begin{tabular}{|c|c|c|c|c|c|c|}
\hline Sample & Phase & $\begin{array}{l}\text { Isomer shift } \\
\quad\left(\mathrm{mm} \mathrm{s}^{-1}\right. \\
\quad \pm 0.005)\end{array}$ & $\begin{array}{c}\text { Hyperfine } \\
\text { field } \\
(\mathrm{kG} \pm 6)\end{array}$ & $\begin{array}{c}\text { Linewidth } \\
\left(\mathrm{mm} \mathrm{s}^{-1}\right. \\
\pm 0.05)\end{array}$ & $\begin{array}{l}\text { Peak position } \\
\quad\left(\mathrm{mm} \mathrm{s} \mathrm{s}^{-1}\right. \\
\pm 0.05)\end{array}$ & $\begin{array}{l}\text { Relative } \\
\quad \text { area } \\
\pm 0.05\end{array}$ \\
\hline \multirow[t]{2}{*}{ R-Fe-E } & $\mathrm{Fe}-\mathrm{Al}$ & - & 一 & 0.47 & -0.06 & 0.45 \\
\hline & $\mathrm{Fc}-\mathrm{Al}$ & 一 & 一 & 0.59 & 0.41 & 0.55 \\
\hline \multirow{3}{*}{$\mathrm{R}-\mathrm{Fe}-\mathrm{F}$} & $\mathrm{Fe}-\mathrm{Al}+\mathrm{Fe}(\mathrm{OH})_{2}$ & - & - & 0.40 & -0.06 & 0.46 \\
\hline & $\mathrm{Fe} \Lambda \mathrm{l}$ & - & - & 0.42 & 0.41 & 0.45 \\
\hline & $\mathrm{Fe}(\mathrm{OH})_{2}$ & 一 & - & 0.38 & 2.46 & 0.09 \\
\hline \multirow{3}{*}{$\mathrm{R}-\mathrm{Fe}-\mathrm{G}$} & $\mathrm{Fe}-\mathrm{Al}$ & - & & $0.44^{h}$ & $0.01^{b}$ & 0.01 \\
\hline & & 一 & - & $0.42^{b}$ & $0.45^{b}$ & 0.04 \\
\hline & Iron metal & 0.01 & 328 & 0.46 & - & 0.92 \\
\hline
\end{tabular}

a Peak positions are with respect to pure iron at $23^{\circ} \mathrm{C}$. Eirrors are estimated at the two-sigma level. For the magnetic hyperfine field spectrum the linewidth given for the two outer lines of the six-line spectrum.

${ }^{b}$ These values were assumed and constrained to be constant during the least-squares fitting.

U-Fe(II) and U-Fe(III), Figs. 5b and c, are representative of a two-phase alloy, one phase being ferromagnetic and the other paramagnetic (or superparamagnetic). The two-phase feature of this material has been demonstrated previously (23). The ferromagnetic phase has been fitted to a superposition of three magnetic hyperfine field spectra. In obtaining these fits the linewidths of all lines in each pattern were constrained to be equal, the areas of the six lines in each pattern were constrained to have a $3: 2: 1: 1: 2: 3$ ratio, and each pattern was constrained to have zero isomer shift. As shown in Fig. 5, this method of fitting gives an adequate, though not pcrfect, representation of the data. Slight improvements could undoubtedly be obtained by removing some of the constraints. This was attempted but difficulties of convergence in the iterative, least-squares fitting procedure were encountered due to the scatter in the experimental data. The fits obtained are considered adequate for our purpose here.

\section{DISCUSSION}

\section{Raney Iron Catalysts}

The parent Raney iron alloy used in this study had a chemical composition equiva- lent to $\mathrm{FeAl}_{2.08}$. From the phase diagram of the $\mathrm{Fe}-\mathrm{Al}$ system (30) the sample should contain approximately $76 \% \zeta$-phase $\left(\mathrm{FeAl}_{2}\right)$ and $24 \% \eta$-phase (the $\eta$-phase field encompasses $\mathrm{Fe}_{2} \mathrm{Al}_{5}$ and has a lower limit corresponding to $\mathrm{Fe}_{2} \mathrm{Al}_{4.67}$ ). As can be seen from Fig. 1 and the data of Table 2, the NGR spectra of $\mathrm{FeAl}_{3}, \mathrm{Fe}_{2} \mathrm{Al}_{5}$, and $\mathrm{FeAl}_{2}$, though not identical, are, for any purposes of phase identification, practically indistinguishable. However, from the NGR spectrum the presence of more than a few percent $\mathrm{FeAl}$ or magnetic $\mathrm{Fe}-\mathrm{Al}$ alloys in the parent Raney iron alloy can be ruled out. The spectrum is compatible with a mixture of $\mathrm{FeAl}_{2}$ and $\mathrm{Fe}_{2} \mathrm{Al}_{5}$ and an X-ray diffraction analysis was also consistent with a sample containing mainly $\mathrm{FeAl}_{2}$ with a smaller amount of $\mathrm{Fe}_{2} \mathrm{Al}_{5}$.

After treating the parent Raney iron alloy with sodium hydroxide at $\simeq 0^{\circ} \mathrm{C}$ for $1.5 \mathrm{hr}$, the spectrum of $\mathrm{Fig}$. If is obtained. A spectrum of the same sample with an increased velocity range is shown in Fig. 4a. Although considerable aluminum has been removed (as evidenced by the release of a large amount of hydrogen during the leaching), there is no evidence in the spectrum for any recrystallization of the Raney alloy into a metallic iron phase, or for the 


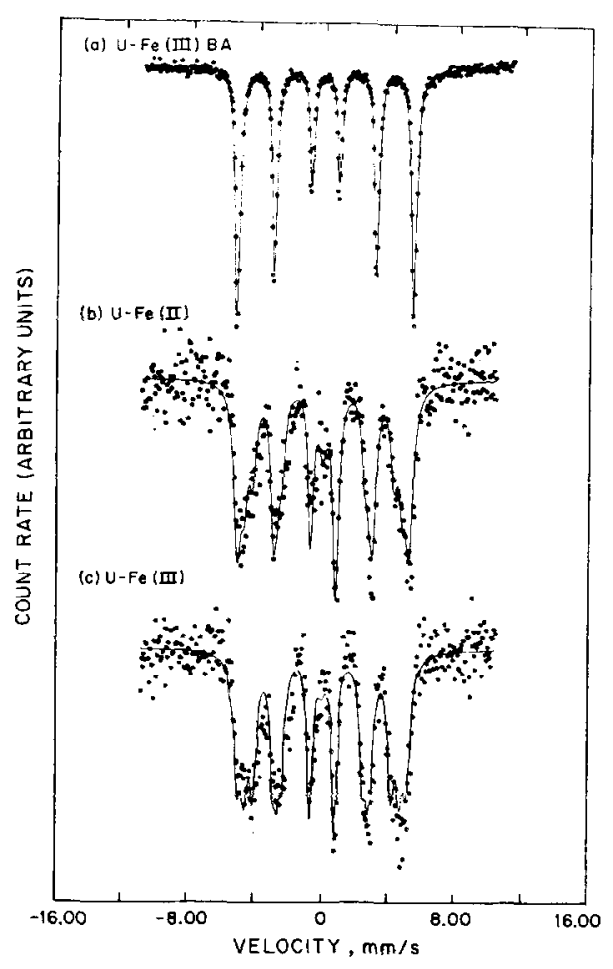

FIG. 5. NGR spectra obtained at $23^{\circ} \mathrm{C}$ for three Urushibara iron catalysts. $(O, 0)$ Experimental data; (-) a least-mean-squares fit obtained as described in the text. The zero of velocity represents the center of a spectrum from pure iron at $23^{\circ} \mathrm{C}$. (a) U-Fe(III)-BA, (b) U-Fe(II), (c) U-Fe(III). presence of any other additional iron phases. There are however, some differences between the spectra of Fig. 1a and 1f. Comparing the data of Table 2 we see that the leached alloy, R-Fe-E, has an increased quadrupole splitting and a broadened linewidth. The increased splitting and linewidth being due to the presence of lattice defects and strains associated with the aluminum removal. There is also the possibility of the existence of very small iron particles which are either superparamagnetic or have very low recoiless fractions. It is also likely that free $\mathrm{Fe}(\mathrm{OH})_{2}$ exists in the $\mathrm{R}-\mathrm{Fe}-\mathrm{E}$ specimen since it has been observed previously (31) that $\mathrm{Fe}(\mathrm{OH})_{2}$ prepared at room temperature does not exhibit a ${ }^{57} \mathrm{Fe}$ spectrum at room temperature due to the small particle size and the effect of adsorbed $\mathrm{H}_{2} \mathrm{O}$ on the precipitate which mitigate against an appreciable recoiless fraction at room temperature. The small particle sizes expected for $\mathrm{Fe}(\mathrm{OH})_{2}$ formed at $0^{\circ} \mathrm{C}$ would further decrease the chances of observing a ${ }^{57} \mathrm{Fe}$ Mössbauer spectrum.

TABLE 6

Parameters Obtained by Least-Squares Fitting the Spectra of Fig. 5 Using the Method Described in the Text ${ }^{a}$

\begin{tabular}{|c|c|c|c|c|c|c|c|}
\hline Sample & Phase & $\begin{array}{l}\text { Peak } \\
\text { No. }\end{array}$ & $\begin{array}{l}\text { Isomer shift } \\
\left(\mathrm{mm} \mathrm{s}^{-1}\right)\end{array}$ & $\begin{array}{l}\text { Peak position } \\
\quad\left(\mathrm{mm} \mathrm{s} \mathrm{s}^{-1}\right. \\
\quad \pm 0.04)\end{array}$ & $\begin{array}{c}\text { Linewidth } \\
\left(\mathrm{mm} \mathrm{s}^{-1}\right)\end{array}$ & $\begin{array}{l}\text { Hyperfine } \\
\text { field } \\
\text { (kG) }\end{array}$ & $\begin{array}{c}\text { Relative } \\
\text { area } \\
\pm 0.05\end{array}$ \\
\hline $\mathrm{U}-\mathrm{Fe}$ (III)-BA & Metallic iron & & $0.00 \pm 0.01$ & 一 & $0.37 \pm 0.02$ & $330 \pm 1$ & 1.0 \\
\hline \multirow[t]{5}{*}{ U-Fe(II) } & $\alpha F e-Z_{n}$ & & $0.0^{b}$ & - & $0.54 \pm 0.04$ & $320 \pm 8$ & 0.45 \\
\hline & $\alpha \mathrm{Fe}-\mathrm{Zn}_{\mathbf{n}}$ & & $0.0^{b}$ & - & $0.54^{b}$ & $295 \pm 10$ & 0.25 \\
\hline & $\alpha \mathrm{Fe}-\mathrm{Zn}$ & & $0.0^{b}$ & 一 & $0.54^{b}$ & $264 \pm 12$ & 0.20 \\
\hline & $\Gamma F e-Z_{I I}$ & 1 & 一 & -0.06 & $0.61 \pm 0.05$ & - & 0.05 \\
\hline & $\mathrm{rFe}-\mathrm{Zn}$ & 2 & 一 & 0.75 & $0.60 \pm 0.05$ & - & 0.05 \\
\hline \multirow[t]{5}{*}{$\mathrm{U}-\mathrm{Fe}(\mathrm{III})$} & $\alpha \mathrm{Fe}-\mathrm{Zn}$ & & $0.0^{b}$ & - & $0.56 \pm 0.04$ & $318 \pm 8$ & 0.34 \\
\hline & $\alpha \mathrm{Fe}-\mathbf{Z}_{\mathbf{n}}$ & & $0.0^{b}$ & - & $0.56^{b}$ & $292 \pm 10$ & 0.33 \\
\hline & $\alpha \mathrm{Fe}-\mathrm{Zn}$ & & $0.0^{b}$ & 一 & $0.56^{b}$ & $260 \pm 12$ & 0.30 \\
\hline & rFe-Zn & 1 & 一 & -0.05 & $0.59 \pm 0.05$ & - & 0.01 \\
\hline & $\mathrm{rFe}-\mathrm{Zn}$ & 2 & - & 0.74 & $0.60 \pm 0.05$ & - & 0.02 \\
\hline
\end{tabular}

a Peak positions and isomer shifts are with respect to pure iron at $23^{\wedge} \mathrm{C}$. Errors are estimaled at the twosigma level. For the magnetic hyperfine field spectra, the linewidth given is for the two outer lines of the six-line magnetic spectrum.

- These values were constrained during the least-squares fitting procedure. 
Upon longer exposure to an alkaline environment at $0^{\circ} \mathrm{C}$, or upon short $c \mathrm{x}$ posure at $1-2 \mathrm{hr}$ between 0 and $20^{\circ} \mathrm{C}$, the Raney alloy treated with alkali at low temperature either reacts to form $\mathrm{Fe}(\mathrm{OH})_{2}$ or the initial, very fine particles of $\mathrm{Fe}(\mathrm{OH})_{2}$ undergo digestion and increase in size as obscrved in Fig. 4b. The latter possibility seems more likcly since there is little evidence of further reaction of the $\mathrm{Fe}-\mathrm{Al}$ alloy. The appearance of the ${ }^{57} \mathrm{Fe}$ NGR spectrum after digestion has also been observed previously (31). Again, no metallic iron particles are observed. If very small superparamagnetic or low recoiless fraction metallic iron particles were present for R-Fe-E, a portion of them would have been expected to grow in size and become observable during the longer leaching period for R-Fe-F. The absence of $\alpha$-Fe in Fig. 4b, and the fact that no change in the spectrum was observed upon application of a $1 \mathrm{kG}$ magnetic field, argues against the presence of any superparamagnetic $\alpha$-Fe. By leaching at the slightly higher temperature of $25^{\circ} \mathrm{C}$, metallic iron is secn to form along with $\mathrm{Fe}(\mathrm{OH})_{2}$ (Fig. 3a).

The calalysts that result from $\mathrm{NaOH}$ leaching of the parent Raney alloy at $80^{\circ} \mathrm{C}$ and above (or for extended leaching at somewhat lower temperatures) contain $\mathrm{Fe}_{3} \mathrm{O}_{4}$ in addition to the metallic $\alpha$-Fe phase. The $\mathrm{Fe}_{3} \mathrm{O}_{4}$ phase is evident in Fig. $2 \mathrm{a}$ and $\mathrm{b}$. The fraction of $\mathrm{Fe}_{3} \mathrm{O}_{4}$ increases with increasing leaching temperature and time. It is interesting to note that sample R-Fe-D, which was leached at $25^{\circ} \mathrm{C}$ first, then at $80^{\circ} \mathrm{C}$ for $45 \mathrm{~min}$, had a larger fraction of $\mathrm{Fe}_{3} \mathrm{O}_{4}$ than $\mathrm{R}-\mathrm{Fe}-\mathrm{A}$ which was initially leached at $90^{\circ} \mathrm{C}$ for $90 \mathrm{~min}$ and then at $95^{\circ} \mathrm{C}$ for $60 \mathrm{~min}$. All these samples with $\mathrm{Fe}_{3} \mathrm{O}_{4}$ present were nonpyrophoric and did not oxidize to any great extent on exposure to air as dry powders. For example, the $\mathrm{Fe} / \mathrm{Fe}_{3} \mathrm{O}_{4}$ ratio of sample $\mathrm{R}-\mathrm{Fe}-\mathrm{A}$, upon exposure to air for $72 \mathrm{hr}$, underwent a decrease from 0.27 to 0.23 . This low rate of oxidation suggests that the iron particles are coated with a $\mathrm{Fe}_{3} \mathrm{O}_{4}$ layer and are protected from additional facile oxidation.
For all the Raney iron catalyst samples studied hore, the NGR parameters of the $\mathrm{Fe}_{3} \mathrm{O}_{4}$ and $\mathrm{Fe}$ phases indicate very little solid solution or alloying, respectively, with $\mathrm{Al}$. The presence of $\mathrm{Al}$ in either of these two phases would tend to decrease the magnetic hyperfine field from that found for pure $\mathrm{Fe}_{3} \mathrm{O}_{4}$ and $\alpha$-Fe, contrary to our findings. It has been shown that $\mathrm{Fe}(\mathrm{OH})_{2}$ can decompose not only according to Eq. (3) but also in the following manner (29) :

$$
4 \mathrm{Fe}_{\mathrm{e}}(\mathrm{OH})_{2} \rightarrow \mathrm{Fe}_{3} \mathrm{O}_{4}+\mathrm{Fe}+4 \mathrm{II}_{2} \mathrm{O} .
$$

There would be no Fe-Al alloying in this case since $\mathrm{Fe}(\mathrm{OH})_{2}$ does not form mixed crystals with $\mathrm{Al}(\mathrm{OH})_{3}$ or $\mathrm{AlOOH}$.

\section{Urushibara Iron Catalysts}

As seen in Fig. 5a, the U-Fe(III)-BA catalyst has a NGR spectrum characteristic of pure $\alpha$-Fe. Just as for the Raney iron catalysts, this $\alpha$-Fe phase could have only a very small amount of alloyed aluminum. When a small amount of $\mathrm{Al}$ is alloyed into $\alpha-\mathrm{Fe}$, the average hyperfine field decreases by approximately $2 \mathrm{kG}$ for each percent of added Al. From the value of the hyperfine ficld obtaince for U-Fe(III)-BA (Table 6) we conclude that the $\alpha$-Fe phase contains less than $0.5 \%$ alloyed aluminum.

The spectra for U-Fe(II) and U-Fe(III) differ considerably from that obtained for $\mathrm{U}-\mathrm{Fe}$ (III)-BA. The U-Fe(II) and UFe(III) preparation procedure differs in that $Z n$, rather than $A l$, is used and in that they are leached in an acid rather than a base. The spectra of Fig. 5b and c can be interpreted as consisting of a ferromagnetic $\alpha$-phase $\mathrm{Fo}_{\mathrm{O}} \mathrm{Zn}$ alloy, and a paramagnetic central doublet of $\Gamma$-phase Fe-Zn. The fitting procedure used for the ferromagnetic Fc-Zn phase was done in analogy with disordered $\mathrm{Fe}-\mathrm{Al}$ alloys, where one expects the hyperfine field, $H_{n}$, for an iron atom surrounded by $n$ nearest-neighbor $\mathrm{Zn}$ atoms to be given approximately by

$$
I_{n}=I_{0}-n \Delta I I .
$$


The effect of second, third, etc., nearestneighbor $\mathrm{Zn}$ atoms is, to a first approximation, a slight further reduction of hyperfine field value and a broadening of each line.

Very little is known about the NGR spectra of $\mathrm{Fe}-\mathrm{Zn}$ alloys, and the spectra of Fig. 5b and $c$ are not sufficiently resolved to permit quantitative conclusions to be drawn. In addition, because of the presence of unreacted zinc, bulk chemical analyses would be ambiguous in determining the composition of the $\mathrm{Fe}-\mathrm{Zn}$ alloys. However, based on the simple considerations above, we would estimate that the $\alpha$-phase of $\mathrm{U}-\mathrm{Fe}(\mathrm{II})$ contains approximately $10 \% \mathrm{Zn}$ and that of U-Fe(III) approximately $13 \%$ zinc. These large amounts of $\mathrm{Zn}$ in the $\alpha$-phase are considerably in excess of what might be expected if only the bulk phase diagram (30) were considered. As has been demonstrated theoretically and experimentally for a number of other alloys systems (31), it is possible that the thermodynamic stability of the small metal particles is such that larger amounts of $\mathrm{Zn}$ can be alloyed in the $\alpha$-phase. Similar enhanced miscibility has been demonstrated for systems such as $\mathrm{Cu}-\mathrm{Os}$, which are almost immiscible in the bulk (32).

\section{CONCLUSIONS}

Four phases are observed to be present in activated Raney iron catalysts, residual aluminum-depleted Raney alloy, $\mathrm{Fe}(\mathrm{OH})_{2}$, $\alpha-\mathrm{Fe}$, and $\mathrm{Fe}_{3} \mathrm{O}_{4}$. The relative proportions of these phases in an activated catalyst are sensitive functions of leaching temperature and time. Optimization of the catalytic activity for any particular process, depending upon whether $\mathrm{Fe}, \mathrm{Fe}_{3} \mathrm{O}_{4}$ or some combination of the two is the active phase, can be accomplished quite easily by using ${ }^{57} \mathrm{Fe}$ NGR to monitor the phase assemblage as the alkali treatment and digestion process

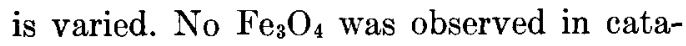
lysts leached at or below $70^{\circ} \mathrm{C}$. For both Raney iron and Urushibara iron prepared using aluminum, no alloying of aluminum into the activated catalyst was observed.
For Urushibara iron prepared using zinc and an acid leach, considerable alloying of zinc and iron is observed in the activated catalyst.

The occurrence of $\mathrm{Fe}-\mathrm{Zn}$ alloying for the Urushibara catalysts U-Fe(II) and U$\mathrm{Fe}$ (III), is believed to be due to the formation of $(\mathrm{Zn}, \mathrm{Fe})(\mathrm{OH})_{2}$ mixed crystals. Otherwise, the synthesis of the Urushibara catalysts appear to follow the same basic mechanism as the Raney catalysts, except for the shorter reaction times and the lower temperatures during the synthesis of the Urushibara catalysts. Thus, it is no surprise that the Urushibara and Raney catalysts are very similar in their catalytic behavior.

In view of the large amounts of $\mathrm{Fe}_{3} \mathrm{O}_{4}$ expected to be present in Raney catalysts prepared according to the usual prescriptions, a careful determination of the activity of finely divided $\mathrm{Fe}_{3} \mathrm{O}_{4}$ in catalyzing the pertinent reactions seems to be in order. Variations in catalytic activity might result from simple variations in relative amounts of $\mathrm{Fe}_{2} \mathrm{O}_{4}$ and $\alpha-\mathrm{Fe}$ and/or in the nature of the association between the two phases, i.e., isolated $\mathrm{Fe}$ and $\mathrm{Fe}_{3} \mathrm{O}_{4}$ particle vs a $\mathrm{Fe}$ core covered with a $\mathrm{Fe}_{3} \mathrm{O}_{4}$ shell or vice versa.

\section{ACKNOWLEDGMENTS}

Partial support of the contribution of B. J. E. to this study by the Donors of the Petroleum Research Fund is gratefully acknowledged. We also thank C. J. Bechtoldt for X-ray analysis and R. D. Robbins and R. L. Parke for technical assistance.

\section{REFERENCES}

1. Kagan, A. S., Kagan, N. M., Ulyanova, G. D., and Dmitrenko, V. E., Sov. Phys. Crystallogr. 15, 1057 (1971).

2. Paul, R., and Hilly, G., Bull. Soc. Chem. Fr. 6, 218 (1939).

3. Freel, J., Pieters, W. J. M., and Anderson, R. B., J. Catal. 16, 281 (1970).

4. Adkins, H., and Pavlic, A. A., J. Amer. Chem. Soc. 69, 3039 (1947).

[5. Kubomatsu, T., Kagału To Kogyo (Osaki) 31, 190 (1957).

6. Kokes, R. J., and Emmett, P. H., J. Amer. Chem. Soc. 81, 5032 (1959). 
7. Freel, J., Robertson, S. D., and Anderson, R. B., J. Catal. 18, 243 (1970).

8. Sato, M., and Ohta, N., Bull. Chem. Soc. Japan 28, 182 (1955).

9. Fouilloux, P., Martin, G. A., Renouprez, A. J., Moraweck, B., Imelik, B., and Prettre, M., J. Catal. 25, 212 (1972); Pearce, C. E., and Lewis, D., J. Catal. 26, 318 (1972); MacNab, J. I., and Anderson, R. B., J. Catal. 29, 328 (1973); 29, 338 (1973).

10. Hata, K., "New Hydrogenating Catalysts." University of Tokyo Press, Tokyo, 1971.

11. Nemoshkalenko, V. V., Rasumov, O. N., and Gorskii, V. V., Phys, Status Solidi 29, 45 (1968).

12. Cser, I.,O tanevich, J., and Pal, L., Phys. Status Solidi 20, 591 (1967); 20, 581 (1967).

13. Stearns, M. B., Phys. Rev. 147, 439 (1966); 168, 588 (1968).

14. Huffman, G. P., and Fisher, R. M., J. Appl. Phys. 38, 735 (1967).

15. Huffman, G. P., J. Appl. Phys. 42, 1606 (1971).

16. Shirane, G., Cox, D. E., and Ruby, S. L., Phys. Rev. 125, 1158 (1962).

17. Schieber, M., Frankel, R. B., Blum, N. A., and Foner, S., J. Appl. Phys. 38, 1282 (1967).

18. Trooster, J. M., and Dymanus, A., Phys. Status Solidi 24, 487 (1967).
19. Hobson, M. C., Jr., Advan. Colloid Interface Sri. 3, 1 (1971).

20. Bartholomew, C. H., and Boudart, M., J. Catal. 29, 278 (1973).

21. Garten, R. L., and Ollis, D. F., J. Catal. 35, 232 (1974).

22. Arnold, D., Kuhnel, S., and Hobart, H., Z. Anorg. Allg. Chem. 379, 35 (1970).

Q3. Evans, B. J., and Swartzendruber, L. J., A. I. P. Conf. Proc. 24, 391 (1975).

24. Wilson, W., and Swartzendruber, L. J., Computer Phys. Commun. 7, 151 (1974).

25. Weismann, I. D., Swartzendruber, L. J., and Bennett, L. H., in "Techniques of Metals Research," (R. F. Bunshah and E. Passaglia, Eds.), Vol. 6, Pt. 2. Wiley, New York, 1973.

26. Miyamoto, H., Shinjo, T., Bando, Y., and Takoda, T., J. Phys. Soc, Japan 23, 1421 (1967).

27. Pritchard, A. M., Haddon, J. R., and Walton, G. N., Corros. Sci. 11, 11 (1971).

28. Linnenbom, V. J., J. Electrochem. Soc. 105, 322 (1958).

29. Shipko, F. J., and Douglas, D. L., J. Phys. Chem. 60, 1519 (1956).

30. Hansen, M., "Constitution of Binary Alloys." MeGraw-Hill, New York, 1958.

31. Ollis, D. F., J. Catal. 23, 131 (1971).

32. Sinfelt, J. H., J. Catal. 29, 308 (1973). 